\title{
Study Case of Optimization Analysis on Energy-saving in Paper Mill Power-Heat System
}

\author{
Huanbin Liu ${ }^{1}$,Jinsong $\mathrm{Tao}^{1}$, Jigeng $\mathrm{Li}^{1}$, Yongjun Yin ${ }^{1}$, Yanming Zhou ${ }^{1}$, and Jinjiang $\mathrm{Jia}^{2}$ \\ ${ }^{1}$ State Key Laboratory of Pulp and Paper Engineering \\ South China University of Technology \\ Tianhe, Guangzhou, Guangdong, 510640(China) \\ Phone/Fax number: +8620 87111363, e-mail: hbliu@scut.edu.cn \\ ${ }^{2}$ Gold East Paper (Jiangsu)Co.,Ltd. \\ No.8, Xing Gang Dong RD., Dagang, ZhenJiang, \\ JiangSu, 212132 (China) \\ Email: j.j.jia@goldeastpaper.com.cn
}

\begin{abstract}
According the characteristics of both steam and power was supplied in paper mill power plant, the optimal running model of the coal-fired power-heat system was researched in this paper. The power plant's physical structure was researched, the superstructure was established and the boiler and turbine running model was analyzed. With the help of mathematical programming, each turbine unit optimal loads were obtained when the same power and steam were produced, moreover, the minimum coal cost were calculated with each boiler unit optimal load distribution. The case study of one paper mill showed that the optimization model was helpful and the coal consumption can decrease $4.7 \%$ aiding with the model.
\end{abstract}

Key words: optimal load distribution; mathematical programming; power-heat system; paper mill

\section{Introduction}

In the recent years, the production of paper mill increased rapidly with the development of economy in China. Meanwhile, the pressure of energy consumption cost also became heavier for most of paper mill managers because energy is the third place cost for one paper mill except fibre material cost and chemical cost. And as the energy conversion section of paper mill, power plant has a great influence on the mill wide energy efficiency, so how to save energy in power plant become an important issue for pulp and paper engineering researchers.

Nowadays, most power plant of paper mill in China is coal-fired power-heat system which supply power for paper machine and other instruments and mainly supply steam to paper machine dry section. And many paper mills have self governed power plant, most of them have more than one turbines and one boilers. For this kind of paper mill power plant, different turbine unit load and boiler unit load will lead to different coal consumption when producing the same power and steam. The turbine unit loads and the boiler unit load were very important because there is an optimal load distribution which will result in the minimum cost.

To get the minimum cost, mathematical programming often be used and mixed-integer linear programming (MILP) is a very general framework for capturing problems with both discrete decisions and continuous variables H.K.Sarimveis [1] used MILP model to optimize a paper mill energy system. M.Bojic [2] used MILP to optimize the cogeneration system of one paper mill, and Hui C. W.[3] optimized one Japanese petrochemical enterprise's power plant with the help of MILP.

In this paper, mathematical programming was also used to get the optimal running model of the coal-fried powerheat system, and after optimization, the minimum cost turbine unit and boiler unit load distribution was obtained.

\section{Boiler Model}

The boiler model is a relationship between boiler efficiency and evaporation at different load. Because the demand fluctuation of steam in paper mill is big, the boiler load will change frequently, it bring some difficult for objective function and constraint function.

\section{A. Objective function}

The objective of boiler unit optimization is to get the minimum coal consumption when meeting the requirement of steam production, as in (1)

$$
\min B=\sum B i
$$


Where $\mathrm{B}$ is total boiler coal consumption; $B i$ is $B i$ boiler coal consumption.

\section{B. Constraint Function}

\section{1) Boiler characteristics constraint function}

Boiler characteristics constraint function reveals the relationship between each boiler coal feeding to evaporation, as in (2) and (3)

$$
\begin{gathered}
B=f\left(S_{i}\right) \\
B_{i}=a_{0} y_{i}+a_{1} S_{i}+a_{2} S_{i}^{2}+\ldots . .+a_{n} S_{i}^{n}
\end{gathered}
$$

Where $\mathrm{B}$ is boiler coal consumption, $\mathrm{Si}$ is the steam outlet of boiler i, $B i$ is boiler i coal consumption.

\section{2) Steam load constrain}

Steam load constrain expresses the turbines requirement to boiler system steam production, as in (4)

$$
\sum_{i=1}^{n} S_{i}=S_{o}
$$

where $S_{o}$ is the total steam production of boiler system.

3) Boiler evaporation constrain

Boiler evaporation constrain means the range of each boiler operation, as in (5)

$$
\left(S_{i}\right)_{\min } \leq S_{i} \leq\left(S_{i}\right)_{\max }
$$

\section{Turbine Model}

The turbine model is to establish the relationship among steam feeding rate with power generation and steam extraction amount.

\section{A. Objective function}

Turbine objective function is to get the minimum steam feeding yet the power generation is still the same, as in (6)

$$
\min S=\sum_{i=1}^{n} S i+\sum_{j=1}^{m} D i
$$

where $S$ is the total steam demand; $\sum_{i=1}^{n} S i$ is the sum of turbine $n$ steam feeding; $\sum_{j=1}^{m} D i$ is the steam feeding sum of turbine $m$ pressure and temperature reducing valve.

\section{B. Constraint Function}

\section{1) Power generation constraint}

This constraint is to meet the power user's requirement, as in (7)

$$
\sum_{i=1}^{n} N_{i}=P
$$

where $N_{i}$ is generated power of turbine $i, P$ is total demand of power.

\section{2) External steam constraint}

The external steam constraint is to meet the requirement of the balance of inlet and outlet steam, as in (8)

$$
\sum_{j=1}\left(S_{\text {in }}\right)_{j-} \sum_{j=1}\left(S_{\text {out }}\right)_{j}=S_{\text {load }}
$$

\section{3) Facility model constraint}

Facility model constraint reveals the relationship among inlet steam, outlet steam and power, for extraction steam turbine, the facility model constraint is as in (9)

$$
S_{\text {in }}=a_{0}+a_{1} N_{i}+a_{2} S_{\mathrm{i} 1}+a_{3} S_{\mathrm{i} 2}
$$

where $S_{i n}$ is steam inlet of turbine $i, N_{i}$ is the generated power of turbine $i, S_{\mathrm{i} 1}$ is the medium pressure extracting steam amount, $S_{\mathrm{i} 2}$ is the low pressure extracting steam amount.

4) Low pressure cylinder minimum inlet steam constrain

Low pressure cylinder must keep a minimum steam flow rate to cool the machine, the constrain is as in (10)

$$
S_{i n}-S_{i 1}-S_{i 2}-\sum S_{i j}>\left(S_{C O N D}\right)_{\min }
$$

where $S_{i j}$ is the extracting steam sum of heating regenerator which usual gets through balance calculation.

\section{5) Maximum inlet constraint}

The maximum inlet constraint is that the real inlet steam must not exceed the design value, as in (11)

$$
S_{i n} \leq S_{i n_{\max }}
$$

where $S_{i n}$ is the real inlet steam; $S_{i n_{\max }}$ is the design inlet steam value.

6) Maximum generation power constraint

In the real operation, turbine can run over rated power, but the optimization must guarantee the safety and keep turbine running below rated power, as in (12)

$$
N_{i}=N_{i \max }
$$

Where $N_{i}$ is the generated power of turbine $i, N_{i \max }$ is the rated generated power of turbine $i$ 。

\section{7) Extracting steam constraint}

To keep turbine working well, the first extracting steam amount and second extracting steam amount can't exceed the set value, and the constraint is as in (13)

$$
\begin{aligned}
& S_{i 1} \leq\left(S_{i 1}\right)_{\max } \\
& S_{i 2} \leq\left(S_{i 2}\right)_{\max }
\end{aligned}
$$


Where $S_{i 1}$, is the medium pressure extracting steam amount of turbine $i, S_{i 2}$ is the low pressure extracting steam amount of turbine $i,\left(S_{i 1}\right)_{\max }$ is the medium pressure maximum extracting steam amount of turbine $i,\left(S_{i 2}\right)_{\max }$ is the low pressure maximum extracting steam amount of turbine $i$.

\section{8) Variable constraint}

Variable constraint limit the range of variable fluctuation, as in (14)

$$
S_{i 1} \geq 0 ; S_{i 2} \geq 0 ; N_{i} \geq 0
$$

\section{Case Research}

Taking one paper mill power plant as the research case. There are four boilers and four turbines. Boiler \#1, 2, 3 and turbine \#1, 2, 3share one steam main pipe and is a main pipe thermal system, and boiler \#4 and turbine \#4 use a separate main pipe and is a unit thermal system. And the turbines and boilers charater is as in Table I and II.

Table I.-Main capacity parameters of turbines

\begin{tabular}{|c|c|c|c|}
\hline \multirow{2}{*}{ Items } & Unit & \multicolumn{2}{|c|}{$\begin{array}{c}\text { Design capacity } \\
\text { parameter }\end{array}$} \\
\cline { 3 - 4 } & & $\# 1$ & $\# 2,3,4$ \\
\hline Rate power & $\mathrm{kw}$ & 50000 & 80000 \\
\hline Steam pressure & $\mathrm{Mpa}$ & 12.3 & 12.3 \\
\hline $\begin{array}{c}\text { Medium pressure } \\
\text { extracting steam pressure }\end{array}$ & $\mathrm{Mpa}$ & 1.6 & 1.6 \\
\hline $\begin{array}{c}\text { Medium extracting steam } \\
\text { amount }\end{array}$ & $\mathrm{t} / \mathrm{h}$ & 30 & $50 / 50 / 90$ \\
\hline $\begin{array}{c}\text { low pressure extracting } \\
\text { steam pressure }\end{array}$ & $\mathrm{Mpa}$ & 0.6 & 0.6 \\
\hline $\begin{array}{c}\text { low pressure extracting } \\
\text { steam amount }\end{array}$ & $\mathrm{t} / \mathrm{h}$ & 145 & $195 / 195 / 3$ \\
00
\end{tabular}

Table II.-Main capacity parameter of boilers

\begin{tabular}{|c|c|c|c|}
\hline \multirow{2}{*}{ Items } & \multirow{2}{*}{ Unit } & \multicolumn{2}{|c|}{$\begin{array}{c}\text { Design capacity } \\
\text { parameters }\end{array}$} \\
\cline { 2 - 4 } & & $\# 1$ & $\# 2,3,4$ \\
\hline $\begin{array}{c}\text { Evaporation } \\
\text { capacity }\end{array}$ & $\mathrm{t} / \mathrm{h}$ & 250 & 400 \\
\hline $\begin{array}{c}\text { Superheated } \\
\text { steam pressure }\end{array}$ & $\mathrm{MPa}$ & 12.5 & 12.5 \\
\hline $\begin{array}{c}\text { Superheated } \\
\text { steam } \\
\text { temperature }\end{array}$ & ${ }^{\circ} \mathrm{C}$ & 537 & 537 \\
\hline $\begin{array}{c}\text { feed-water } \\
\text { temperature }\end{array}$ & ${ }^{\circ} \mathrm{C}$ & 140 & 140 \\
\hline
\end{tabular}

\begin{tabular}{|c|c|c|c|}
$\begin{array}{c}\text { hot air } \\
\text { temperature }\end{array}$ & ${ }^{\circ} \mathrm{C}$ & 170 & 170 \\
\hline $\begin{array}{c}\text { Exhaust air } \\
\text { temperature }\end{array}$ & ${ }^{\circ} \mathrm{C}$ & 145 & 145 \\
\hline Coal & & $\begin{array}{c}\text { bituminous } \\
\text { Coal III }\end{array}$ & $\begin{array}{c}\text { bituminous } \\
\text { Coal III }\end{array}$ \\
\hline boiler efficiency & $\%$ & 91.7 & 91.7 \\
\hline
\end{tabular}

\section{A. Turbine model}

\section{1) Turbine \#4 model}

Turbine \#4 rated power is $80 \mathrm{MW}$, principal steam temperature is $535^{\circ} \mathrm{C}$ and principal steam pressure is $12.3 \mathrm{MPa}$, Based on the running data provided by the paper mill, the relationship among inlet steam amount, medium pressure extracting amount, low pressure extracting amount and generated power is as in Figure 1.From Figure 1, the linear relationship can be found among inlet steam amount and medium pressure extracting amount, low pressure extracting steam amount and generated power.

The regression model can be got as Table III with the help of SPSS (Statistical Package for the Social Sciences), and it has good linear relationship and the correlation coefficient is 0.998 .

Table III. - Turbine \#4 regression model

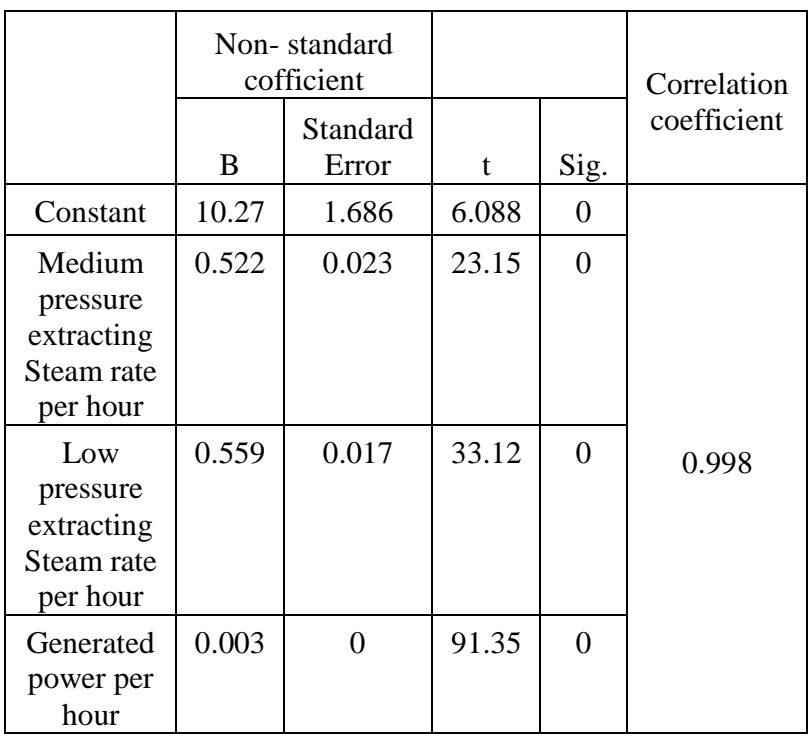

And Turbine \#4 running model can be got as in (15)

$S_{4}^{\prime}=0.522 S_{4 m}+0.559 S_{4 L}+0.003 N_{4}+10.265$

Where $190 \leq S_{4}^{\prime} \leq 400 \mathrm{t} / \mathrm{h}, \quad 20 \leq S_{4 m} \leq 65, \quad 30 \leq S_{4 L} \leq 130$,

$N_{4} \leq 80000$ 。 


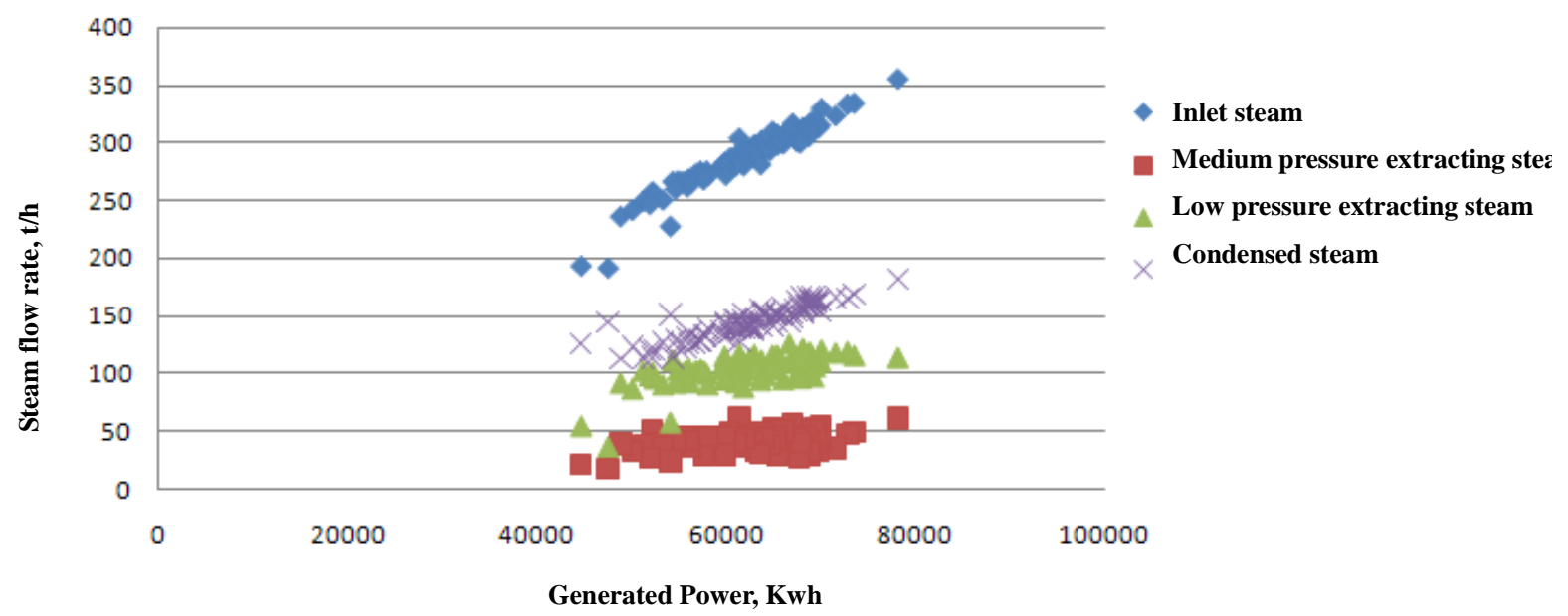

Fig.1 Turbine \#4 running plot

\section{2) Turbine \#1, 2, 3 models}

The rated power of turbine \#1, 2, 3 is $50 \mathrm{MW}, 80 \mathrm{MW}$ and $80 \mathrm{MW}$, principal steam temperature is $535^{\circ} \mathrm{C}$, pricipal steam pressure is $12.3 \mathrm{MPa}$, and the regression models of turbine \#1,2,3 are as in (16), (17) and (18)

Turbine\#1

$S_{1}^{\prime}=0.715 S_{1 m}+0.443 S_{1 L}+0.004 N_{1}+13.954$

Turbine \#2:

$S_{2}^{\prime}=0.628 S_{2 m}+0.395 S_{2 L}+0.003 N_{2}+18.211$

Turbine \#3:

$S_{3}^{\prime}=0.542 S_{3 m}+0.449 S_{3 L}+0.003 N_{3}+17.427$

where

$140 \leq S_{1}^{\prime} \leq 250, \quad 5 \leq S_{1 m} \leq 30, \quad 35 \leq S_{1 L} \leq 100, \quad N_{1} \leq 50000 ;$

$170 \leq S_{2}^{\prime} \leq 330, \quad 10 \leq S_{2 m} \leq 45, \quad 45 \leq S_{2 L} \leq 140, \quad N_{2} \leq 80000 ;$

$130 \leq S_{3}^{\prime} \leq 350, \quad 10 \leq S_{3 m} \leq 45, \quad 45 \leq S_{3 L} \leq 140, \quad N_{3} \leq 80000 ;$

\section{B. Boiler model}

Boiler \#1,2,3,4 are all circulating fluidized boiler and each boiler capacity parameters are as in Table II.

\section{1) Boiler \#4 running model}

Boiler \#4 rated evaporation capacity is $400 \mathrm{t} / \mathrm{h}$, principal steam temperature is $537^{\circ} \mathrm{C}$, principal steam pressure is $12.5 \mathrm{MPa}$, and the relationship between coal consumption and steam outlet is as in Figure 2.

From Figure 2, the model coefficient of boiler \#4 can be got as Table IV.
Table IV.-Model coefficient of boiler \#4

\begin{tabular}{|c|c|r|r|r|r|c|c|}
\hline \multicolumn{4}{|c|}{ Model summary } & \multicolumn{3}{c|}{ Coefficient estimate value } \\
\hline $\mathrm{R}^{2}$ & $\mathrm{~F}$ & df1 & \multicolumn{1}{|c|}{ df2 } & Sig. & constant & b1 & \multicolumn{1}{c|}{ 2 } \\
\hline 0.96 & 937.94 & 2 & 78 & 0 & -0.768 & 0.175 & $\begin{array}{r}4.75 \mathrm{E}- \\
05\end{array}$ \\
\hline
\end{tabular}

From Figure 2 and Table IV, a good linear relationship between coal consumption and steam output for boiler \#4 and $\mathrm{R}^{2}$ is $0.96, \mathrm{~F}$ is 937.94 .

Boiler \#4 running model is as (19)

$$
B_{4}=-0.768+0.17502 S_{4}-0.0000475 S_{4}^{2}
$$

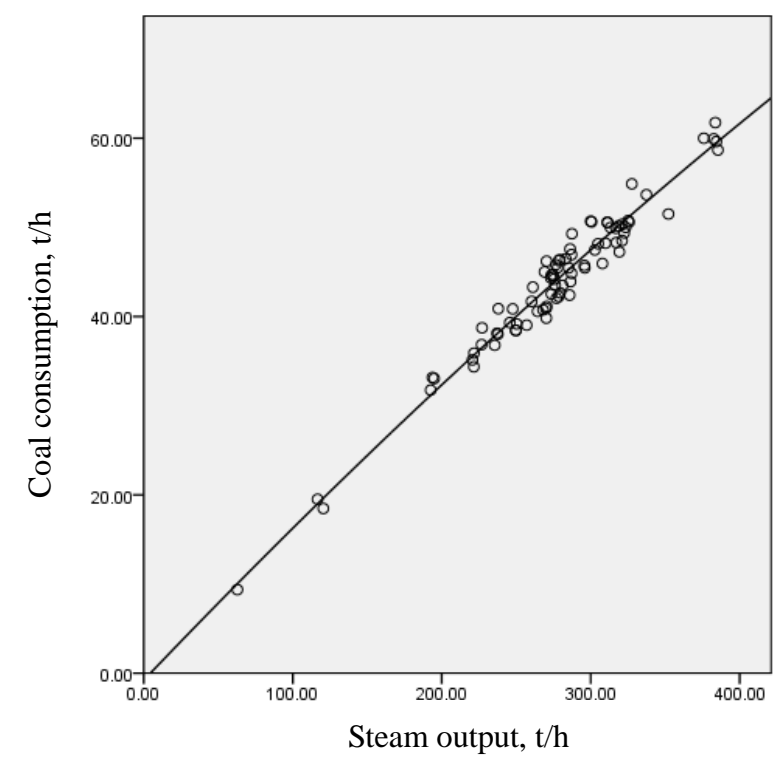

Fig.2 Boiler \#4 charateristics curve between coal consumption and steam output

\section{2) Boiler \#1, 2, 3 running model}

With the same step as boiler \#4, boiler \#1, 2, 3 running model can be got as (20), (21) and (22)

$$
B_{1}=-11.905+0.27847 S_{1}-0.000301 S_{1}^{2}
$$




$$
\begin{gathered}
B_{2}=-8.308+0.22482 S_{2}-0.000125 S_{2}^{2} \\
B_{3}=-10.134+0.24045 S_{3}-0.000176 S_{3}^{2}
\end{gathered}
$$

Where, $150 \leq S_{1} \leq 240 ; 230 \leq S_{2} \leq 390 ; 200 \leq S_{3} \leq 400$;

$120 \leq S_{4} \leq 390$

\section{C.Optimization result}

According to the power plant process structure of the paper mill, the supercontruct can be obtained as in Figure 3. Based on the superstructure, the paper mill power plant non-linear programming model (NLPM) can be established. The objective constraint function is the minimum coal consumption, and medium pressure steam, low pressure steam and power demand refer to the real operation, and the other constraint can be got as energy balance calculation and material balance calculation.

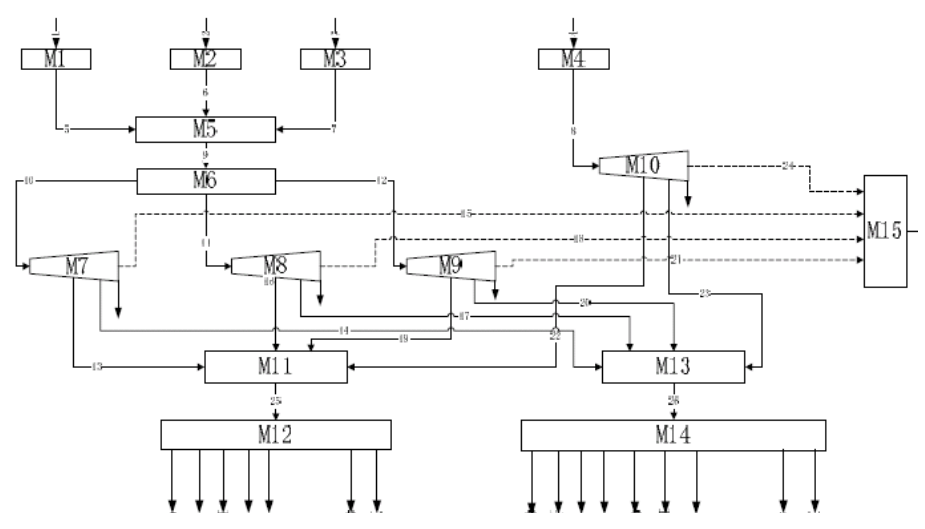

Fig.3 The superstructer of the paper mill power plant

Table V. -Optimization result of boilers

\begin{tabular}{|c|c|c|c|c|c|c|c|c|c|c|}
\hline \multirow{2}{*}{ Items } & \multicolumn{2}{|c|}{ Boiler \#1 } & \multicolumn{2}{c|}{ Boiler \#2 } & \multicolumn{2}{c|}{ Boiler \#3 } & \multicolumn{2}{c|}{ Boiler \#4 } & \multicolumn{2}{c|}{ SUM } \\
\cline { 2 - 11 } & After & Before & After & Before & After & Before & After & Before & After & Before \\
\hline $\begin{array}{c}\text { Coal } \\
\text { consumption, } t / h\end{array}$ & 23.093 & 24.99 & 42.021 & 43.56 & 53.882 & 42.72 & 19.74 & 43.45 & 138.74 & 154.72 \\
\hline Steam output, $t / h$ & 150 & 177.06 & 262.04 & 266.34 & 362.67 & 264.21 & 121.16 & 263.73 & 895.87 & 971.34 \\
\hline
\end{tabular}

Table VI.-Optimization result of turbines

\begin{tabular}{|c|c|c|c|c|c|c|c|c|c|c|c|}
\hline \multirow{2}{*}{ Items } & \multicolumn{2}{|c|}{ Turbine \#1 } & \multicolumn{2}{c|}{ Turbine \#2 } & \multicolumn{2}{c|}{ Turbine \#3 } & \multicolumn{2}{c|}{ Turbine \#4 } & \multicolumn{2}{c|}{ SUM } \\
\cline { 2 - 11 } & After & Before & After & Before & After & Before & After & Before & After & Before \\
\hline Steam inlet, t/h & 140 & 177.06 & 255.14 & 266.34 & 251.88 & 264.21 & 248.85 & 263.73 & 895.87 & 971.34 \\
\hline $\begin{array}{c}\text { Medium pressure } \\
\text { extracting steam } \\
\text { rate,t/h }\end{array}$ & 5 & 15.35 & 10 & 27.97 & 29.79 & 33.04 & 65 & 33.43 & 109.79 & 109.79 \\
\hline $\begin{array}{c}\text { Low pressure } \\
\text { extracting steam rate, } \\
\text { t/h }\end{array}$ & 85 & 69.57 & 140 & 73.29 & 100.65 & 107.20 & 30 & 104.40 & 354.46 & 354.46 \\
\hline $\begin{array}{c}\text { Generated power, } \\
\text { kwh }\end{array}$ & 21204 & 35690 & 58451 & 45597 & 57883 & 57323 & 62628 & 61556 & 200166 & 200166 \\
\hline
\end{tabular}

The established model is a NLPM, and there are twenty seven variables, fifteen equation constraint, four inequation constraint and eight indipendent variables. Aid with MATLAB non-linear programming function, fmincon, theoptimization result can be got as Table V, and Table VI.

From Table $\mathrm{V}$, the coal consumption after optimization is $138.74 \mathrm{t} / \mathrm{h}$ and it is $154.72 \mathrm{t} / \mathrm{h}$ before optimization, that's to say, $15.98 \mathrm{t} / \mathrm{h}$ coal is saved , and the steam output is 895.87 $\mathrm{t} / \mathrm{h}$. And from Table VI, when feeding $895.87 \mathrm{t} / \mathrm{h}$ steam, the turbines also can produce the same medium pressure extraction steam, low pressure extracting steam and power.

According to the optimization result, when adjusting the boiler and turbines load distribution, the minimum coal consuption can be obtained.

\section{Conclusion}

The boiler and turbine load distribution optimization is an important method for paper mill power plant economical operation and energy saving, it can reduce the energy consumption and exhaust emission and improve profile and environment.

\section{Acknowledgement}

The authors would like to acknowledge the financial support of Guangdong-KongHong Key Field Researching Foundation ( Grant No.20070109-2 ) , Guangdong Province Science and Technology Project Foundation 
(Grant No. 2007B050200010) , Natural Science Foundation of China (Grant No. 20906030) and State Key Laboratory of Pulp and Paper Engineering Youth Innovation Program Foundation, South China University of Technology.

\section{References}

[1]. H. K. Sarimveis, T. R. Retsina, S. R. Rutherford, G. V. Bafas, "Energy Conversion and Management", 2003. 44(10): pp. $1707-1718$

[2]. M. Boji, "Energy Conversion and Management", 1998. 39( 7): pp. 637-642.

[3]. Hui C. W., H.Yukikazu, "An industrial application using mixed-integer Programming technique: a multi-Period utility system model". Computers chem, 1996. 20: pp. S1577-S1582. 
